\title{
Evaluation of Changes in Skin Reactivity by Skin Prick Test Titration
}

Sten Dreborg ${ }^{1^{*}}$, Margareta Holgersson ${ }^{2}$ and Christian Moller ${ }^{3}$

${ }^{1}$ Academic University Hospital, Department of Women's and Children's Health, Department of Pediatric Allergology, Uppsala, Sweden

${ }^{2}$ Department on Statistics, Pharmacia Diagnostics, Uppsala, Sweden

${ }^{3}$ Department on Pediatric Allergology, University Hospital, Umea, Sweden

*Corresponding author: Sten Dreborg, Professor Pediatric Allergology, Department of Women's and Children's Health, University Hospital, SE-751 85 Uppsala, Sweden, Tel: 46-733423341; E-mail: sten.dreborg@kbh.uu.se, sten.dreborg@telia.com

Received date: March 14, 2016, Accepted date: April 13, 2016, Published date: April 19, 2016

Copyright: ( 2016 Dreborg S, et al. This is an open-access article distributed under the terms of the Creative Commons Attribution License, which permits unrestricted use, distribution, and reproduction in any medium, provided the original author and source are credited.

\begin{abstract}
Background: Parallel line bioassay (PLBA) has been acknowledged being the gold standard for estimation of changes in skin reactivity during (immuno-)therapy.
\end{abstract}

Objective: To study changes in skin prick test (SPT) estimated by skin prick test titration, wheal area and sum of wheal areas in relation to PLBA.

Methods: Data from a published immunotherapy trial using skin titration with half 10 log steps were evaluated using endpoint titration, wheal areas, histamine equivalent allergen concentration using PLBA as gold standard.

Results: Endpoint titration and PLBA correlated $(r=0.76)$ and the slope of the correlation, $b(0.8)$ was not significantly different from 1, i.e. expressed the same result, were interchangeable. Furthermore, the result was expressed in change in allergen concentration, $\mathrm{Ca}$. The area of all wheals and the area of the wheal induced by the highest concentration also correlated, but to a lesser degree ( $b=0.36$ and 0.41 , respectively), to PLBA significantly different from 1, i.e. did not express the same result.

Conclusions: Estimation of the SPT during therapy expressed as change in endpoint concentration correlated to changes by PLBA. However, earlier described simple methods, expressing the change in skin sensitivity as change in histamine equivalent concentration, should be preferred.

Keywords: Skin prick test; Allergen; Histamine; Method; Allergy; Immunotherapy; Wheal area; Wheal diameter; Skin prick test titration.

\begin{abstract}
Abbreviations
A: Wheal area in $\mathrm{mm}^{2}$; Aa: Mean wheal area induced by a given allergen concentration; $b$ : The slope of the allergen dose response relationship (model: $\mathrm{A}=\mathrm{a}+\mathrm{b} \log$ conc.); $\mathrm{Ch}$ : Histamine equivalent allergen concentration; CPT: Conjunctival provocation test; drra: Allergen dose response relationship; b-drra: The slope of the allergen dose response relationship; PLBA: Parallel line bioassay; $r$ : The coefficient of variation; SPT: Skin prick test; $\delta$ SPT: Change in skin sensitivity; $\mathrm{X}$ : $\mathrm{X}$ indicates methods used as $\mathrm{X}$ variables; $\mathrm{Y}$ : $\mathrm{Y}$ indicates methods used as y variables.
\end{abstract}

\section{Introduction}

Some decades ago, most allergists used endpoint titration by intradermal skin testing as a measure of skin reactivity and for determination of starting dose for immunotherapy [1]. During the 1980's European manufacturers started to deliver extracts for SPT in one concentration. Since then results have been reported in terms of wheal diameter, or in some scientific reports in $\mathrm{mm}^{2}$. It has not been possible to compare changes in skin test wheal sizes with that of bronchial, nasal or conjunctival provocation tests reported by threshold concentrations. Furthermore, due to the flat allergen wheal dose response [2,3] a 10-fold increase in skin sensitivity roughly corresponds to an increase in wheal diameter from $3 \mathrm{~mm}$ to $4.65 \mathrm{~mm}$, or from 4.65 to $7.2 \mathrm{~mm}$, or from 7.2 to $11.1 \mathrm{~mm}$ in diameter [4]. Thus, wheals 3 and $11 \mathrm{~mm}$ in diameter represent a thousand-fold difference in reactivity. However, data on change in threshold concentrations are, with few exceptions, not used in clinical trials and still less in clinical practice.

The skin response to SPT in an individual depends on the technique applied but also other factors, such as medication, the total allergenic potency and composition of allergen extracts $[5,6]$. The variation in wheal size between investigators can be minimized by adjusting the allergen wheal size to that of the histamine wheal size [7]. Methods for evaluation of allergen skin reactivity by equilibrating the allergen wheal reaction to that of histamine using the allergen dose response relationship have been developed [8].

Parallel line bioassay, PLBA, is regarded the gold standard for estimating differences in potency and skin reactivity [9].

The aim of the present study was to evaluate skin prick test end point titration, expressing the results as the change in end point or "threshold concentration" from before and after (immuno-)therapy related to estimation of change of skin sensitivity using PLBA. 


\section{Material and Methods}

\section{Patients}

Thirty-nine (39) Swedish children with a clinical history of deciduous tree pollen rhino-conjunctivitis were included, 25 boys and 14 girls, mean age 11 years (range 6-16 years) [10]. The subjects had positive SPT responses to birch, alder, hazel and oak, positive CPT tests for birch, and positive in vitro IgE results to birch [10] ( $>0.35$ Phadebas RAST units $/ \mathrm{ml}$ ). The mean pretreatment CPT threshold concentration of birch freeze-dried allergen extract (Pharmacia Diagnostics $A B$, Uppsala, Sweden) was 1000 Nordic Biological Units/ml (2 $\mu$ g of Bet $v s$ $1 / \mathrm{ml}$ ) [11], and the histamine $1 \mathrm{mg} / \mathrm{ml}$ equivalent birch allergen concentration $\left(\mathrm{C}_{\mathrm{h}}\right)[8] 4800 \mathrm{BU} / \mathrm{ml}$ (about $10 \mu \mathrm{g} / \mathrm{ml}$ ) (Pharmacia). One group, n 19, was given birch allergen extract, while the other group, $\mathrm{n} 20$, was given a deciduous tree mix containing equal amounts of birch, alder and hazel pollen allergen as measured by Nordic Biological Units [12]. The trial was double blinded, randomized.

The original trial was approved by the local ethical committee and parents/care-givers gave their written informed consent.

\section{Test solutions and other materials for SPT and CPT}

Children were tested with several deciduous tree pollen extracts. The results reported here are for a crude oak pollen allergen extract, $1 / 10 \mathrm{w} / \mathrm{v}$, freeze-dried (Pharmacia Diagnostics AB, Uppsala, Sweden).

Positive reference was histamine dihydrochloride $1 \mathrm{mg} / \mathrm{ml}(5.43$ $\mathrm{mmol} / \mathrm{L}$ or $0.63 \mathrm{mg} / \mathrm{ml}$ histamine base) (Pharmacia). For SPT and CPT, Albumin diluent ${ }^{\circ}$ (Pharmacia), was used for reconstitution and as negative control.

The same batch of freeze-dried extract was used before and after immunotherapy. The freeze-dried extracts were reconstituted with Albumin diluent every week.

The potency was given in Nordic Biological Units/ml [12]. One hundred thousand $\mathrm{BU} / \mathrm{ml}$ concentrations contained about $100 \mu \mathrm{g} / \mathrm{ml}$ of major allergen, \pm a factor of 2 [11].

Disposable short beveled $26 \mathrm{G}$ needles were used for SPT in accordance with Pepys $[13,14]$. SPT was performed and recorded according to the EAACI position paper [6].

\section{Materials for immunotherapy}

Subcutaneous immunotherapy (SCIT) was given in a double-blind manner using either a freeze-dried birch allergen preparation (Pharmalgen ${ }^{\circ}$, Pharmacia) or a tree mix (33\% of each of birch, alder and hazel, based on BU) (Pharmalgen ${ }^{\circ}$ tree mix, Pharmacia). Both preparations had a total allergenic activity of $100,000 \mathrm{BU} / \mathrm{ml}$. The Bet $\mathrm{v}$ 1 content of $100,000 \mathrm{BU} / \mathrm{ml}$ was $200 \mu \mathrm{g} / \mathrm{ml}$ [10]. Depot diluent ${ }^{\circ}$ (aluminum hydroxide $0.2 \%$, Pharmacia) was used for maintenance therapy. For up dosing, Albumin diluent ${ }^{\oplus}$ was used.

\section{Skin prick test methods}

Single tests were made with half 10 log dilutions.

In principle, the criteria set out in the EAACI position paper on skin testing were followed [6], e.g., the allergen wheal size was accommodated for the wheal response to the negative control. The weal areas were measured using a digitizer.

\section{Methods for evaluation of changes of skin reactivity}

For all methods the data before and after immunotherapy were compared. Immunotherapy was given for 3 years [10]. The letters A-D identify methods and the number attached to the method letter indicates the number of randomly selected replicates with the same concentration.

End point titration: The lowest concentration eliciting a wheal with an area $\geq 7 \mathrm{~mm}^{2}$, i.e., a mean wheal diameter of $\geq 3 \mathrm{~mm}$, was regarded the cutoff limit. Changes were expressed as change in endpoint concentration, $\mathrm{C}_{\mathrm{a}}$.

Wheal size: The wheal area obtained with the same concentration of allergen was compared before and after immunotherapy. Changes were expressed as change in allergen wheal area, $A_{a}$.

The sum of all wheal areas: The sum of all wheal areas $\geq 7 \mathrm{~mm}^{2}$, i.e., with a mean diameter $\geq 3 \mathrm{~mm}$. Changes were expressed as change in allergen wheal area, $\mathrm{A}_{\mathrm{a}}$.

Parallel line bioassay: Parallel line bioassay was performed according to Finney $[15,16]$. In principle the regression line estimating the allergen dose response relationship $\left(\operatorname{drr}_{\mathrm{a}}\right)$ was calculated before and after immunotherapy and tested for parallelism. When the null hypothesis for parallelism could not be rejected, then the relative change in concentration of allergen needed to elicit a wheal of the same size, before and after immunotherapy, was calculated for each patient. The principle is illustrated in Figure 1. Changes were expressed as change in allergen concentration, $\mathrm{C}_{\mathrm{a}}$.

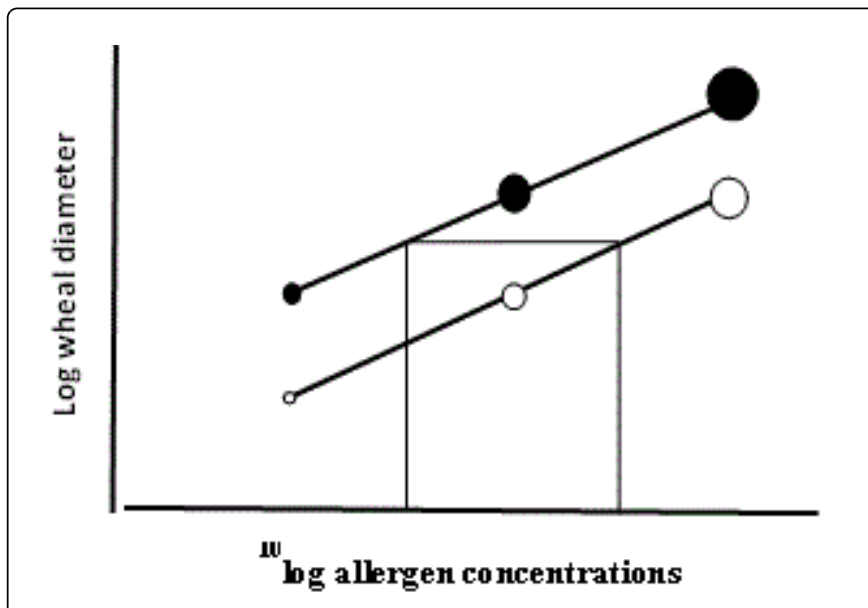

Figure 1: The figure illustrates one patient tested with three ten-fold concentrations of allergen before (above) and after (below) (immuno-)therapy. The dose response should satisfy criteria for parallelism.

\section{Two simple methods for estimation of the histamine equivalent allergen concentration}

Two methods [8] using single histamine and allergen concentrations for estimation of the histamine equivalent allergen concentration $\left(C_{h}\right)$ were documented and changes were found correlating to changes as measured by the PLBA method and CPT in a previous paper [9]. 


\section{Statistical analysis}

Logarithmic transformation of all variables was performed prior to calculation of the relationships described below. The mean wheal area therefore means the geometric mean of wheal areas (the arithmetic mean of logged wheal areas).

The different methods were compared in terms of correlation coefficients calculated by the model $\mathrm{X}=\mathrm{a}+\mathrm{bY}$, as estimated by the method of least squares, where $X=$ change in skin sensitivity as measured by method $\mathrm{X}(\mathrm{A}-\mathrm{D})$ and $\mathrm{Y}=$ change in skin sensitivity as measured by method $\mathrm{Y}$ (A-D). The variable "Change in skin sensitivity" was measured as the relative change in allergen concentration (methods A and D), the change in mean wheal area (method B) or the sum of wheal areas $>7 \mathrm{~mm}^{2}(\operatorname{method} \mathrm{C})$.

Difference in slope from 0 (dose response relationship) and 1 (measuring the same thing) was estimated using the $t$-test.

Bland-Altman analyses [17] were not performed since their paper appeared in the autumn of 1986 at the time we performed our calculations.

\section{Results}

The change in skin sensitivity as measured by methods A, B and C versus method $\mathrm{D}$ (the gold standard), and methods $\mathrm{B}$ and $\mathrm{C}$ versus method A (the endpoint titration method), is shown in Table 1.

\begin{tabular}{|c|c|c|c|c|c|c|}
\hline \multirow[t]{2}{*}{ Allergen } & \multicolumn{2}{|c|}{ SPT method } & \multirow{2}{*}{$\begin{array}{l}\text { Conc. BU/ml } \\
\times 1000\end{array}$} & \multirow[t]{2}{*}{$\mathbf{n}$} & \multirow[t]{2}{*}{$\mathbf{r}$} & \multirow[t]{2}{*}{$\mathbf{b}^{1}$} \\
\hline & Y-axis & X-axis & & & & \\
\hline \multirow[t]{5}{*}{ Birch } & $A$ & $D$ & & 33 & 0.76 & $0.80^{2}$ \\
\hline & B & $D$ & 2,000 & 33 & 0.83 & 0.36 \\
\hline & C & $\mathrm{D}$ & & 19 & 0.90 & 0.41 \\
\hline & B & A & 2,000 & 39 & 0.63 & 0.23 \\
\hline & C & A & & 24 & 0.80 & 0.32 \\
\hline
\end{tabular}

1) The lopes, b, were significantly different from $0(p<0.0001)$ and significantly different from 1.

2) Not significantly different from 1 , significantly different from $0(p<0.0001)$.

Table 1: Correlations between changes in skin sensitivity as measured by different SPT methods. A is the endpoint titration method, B is the wheal area method, $C$ is the sum of the wheal area method and D is the parallel line bioassay method. $\mathrm{n}$ denotes the number of eligible patients, $r$ is the coefficient of correlation, $b$ denotes the slope.
All correlations ( $\mathrm{r}$ ) except for method B to A were higher than 0.75 and the correlations of methods B and C, i.e., the methods based on areas, to method $\mathrm{D}$ were higher than 0.8 , i.e., an indication the methods are interchangeable (Table 1). However, methods B-C express the change in wheal size, $A_{a}$, and methods $A$ and $D$ that of $C_{a}$.

The intercept, a, was not significantly different from 0 , i.e., the ratio between the results obtained with different methods was similar at high and low response levels.

\section{Discussion}

This study shows that several methods for estimating changes in skin reactivity during SCIT correlate well with the gold standard, PLBA. In a previous study [9] this has also been shown for two simple methods, using one allergen concentration and the slope of the allergen dose response relationship (b-drr ${ }_{a}$ ) [8]. These simple methods [8] estimating changes in skin histamine equivalent threshold concentrations are also appropriate for evaluation of the change of skin reactivity during (immuo-)therapy and in patients/patient samples over time [9].

In our previous paper on evaluation of immunotherapy using the two simple methods [9], we found good correlation between changes in shock organ sensitivity (CPT) and skin sensitivity. This makes it possible to follow the allergen-specific effect of immunotherapy using skin tests performed at different times during (immuno-) therapy. A prerequisite is the precision of the SPT technique is good. Then both end point titration and, as demonstrated in our previous study, the simple methods, can be used. Preferably, the differences in technique, between testing personnel and occasions, should be minimized by relating the allergen wheal response to that of the histamine reference, thus correcting for differences in technique and possible changes in general skin reactivity. Actually, the endpoint concentration can be recalculated as the histamine equivalent concentration, $\mathrm{C}_{\mathrm{a}}$.

There was a high correlation between changes in skin test endpoint titration and PLBA (Table 1). Both methods deliver results that indicate a difference in skin reactivity based on allergen concentration that elicits a given response. The endpoint of allergen skin titration is defined as the lowest allergen concentration eliciting a wheal but higher than that the cut-off, i.e., the mean of the background+3.3 s.d. The background should be determined per device. There are data on the cut-off limit for American SPT devices [18] (Table 2 in [19]) but not for European SPT devices $\S$.

§In the AAAAI/ACAAI Practice Parameter on diagnosis, 2008 (18), is given data for an "ALK" lancet. However, it is an American version, not the Østerballe steel lancet commonly used in Europe.

All slopes (b), using the model Log Area $=a+b l o g$ concentration, were significantly different from $0(\mathrm{p}<0.0001)$, i.e., there was a dose response relationship.

\begin{tabular}{|l|l|l|l|}
\hline $\begin{array}{l}\text { Device 1 } \\
\text { Devices for which a 3-mm wheal would } \\
\text { be significant }\end{array}$ & $\begin{array}{l}\mathbf{0 . 9 9} \text { Quintile of reactions at } \\
\text { the negative control sites, } \\
\mathbf{m m}\end{array}$ & $\begin{array}{l}\text { Device 2 } \\
\text { Devices for which a more than 3-mm wheal } \\
\text { should be used as significant. }\end{array}$ & $\begin{array}{l}\text { 0.99 Quintile of reactions at the } \\
\text { negative control sites, mm }\end{array}$ \\
\hline Quintest (HS) puncture & 0 & DuoTip (Lincoln) twist & 3.5 \\
\hline Smallpox needle (HS) prick & 0 & Bifurcated needle (ALO) prick & 4.0 \\
\hline
\end{tabular}


Page 4 of 5

\begin{tabular}{|l|l|l|l|}
\hline DuoTop (Lincoln) prick & 1.5 & MultiTest (Lincoln) puncture & 4.0 \\
\hline Lancet (HS) & 2.0 & Bifurcated needle (ALO) puncture & 4.5 \\
\hline Lancet (ALK) & 3.0 & Quick Test (Pantrex) & 4.0 \\
\hline DermaPICK II & 0 & Greer Track (Greer) & 3.5 \\
\hline Abbreviations: HS: Hollister Steer; Greer: Greer Laboratories; ALO: Allergy Labs of Ohio; Lincoln: Lincoln Diagnostics; ALK: ALK. \\
\hline
\end{tabular}

Table 2: The size of wheals that are larger than $99 \%$ of the wheals with saline, using the same device on subject's back by the same operator ( $\mathrm{n}=$ 80) [18].

End point titration or pricking one allergen concentration and histamine estimating $C_{a}$ are basis for meaningful reporting of changes in skin reactivity comparable to the threshold concentrations of challenge procedures. The results are therefore more meaningful than reporting the size of allergen induced wheals, as obtained with methods B and C. The endpoint titration is laborious and difficult to interpret, especially if the precision of the testing personnel is not optimal, since bad precision may cause the first positive skin reaction to be followed by a negative reaction at a higher concentration.

A decrease in histamine wheal size from before to after SCIT has been reported in several immunotherapy trials $[9,19]$. Stuckey et al., found the size of histamine wheals to be correlated to total IgE and the number of sensitizing allergens [20]. Bordignon and Burastero [21] found a correlation between the number of positive allergen skin prick tests and sensitivity to histamine (mono-sensitized versus polysensitized subjects: $p=0.0015)$ [21]. As indicated in [9] a decreased sensitivity to the allergen used for SCIT may therefore explain the decrease in histamine wheal size. Another explanation may be a change of technique. Whatever the reason, the allergen response should be interpreted in relation to the skin reactivity on the same occasion [7]. The three methods for estimation of changes of skin sensitivity during allergen immunotherapy investigated in this communication (methods A-C) do not use histamine for equilibration of changes in skin reactivity and/or changes in testing technique that makes them less useful than the simple methods including histamine "correction".

As mentioned in our previous communication [9], the correlations between changes in CPT threshold concentration, the reference method D and the two investigated simple methods using the common slope $b$ of the $\mathrm{drr}_{\mathrm{a}}$ were good. Skin testing can therefore be used as a surrogate for organ provocation. However, the simple methods should be preferred in studies as well as in clinical practice, since they report a threshold concentration.

In conclusion, changes in SPT reactivity can be estimated by endpoint titration and wheal area/diameter. However, earlier described methods estimating the change in allergen concentration that elicits a wheal of the size of the histamine reference, minimizing the influence of differences in technique between test occasions and testing personnel, should be preferred. This measure of skin sensitivity is well correlated to shock organ sensitivity.

\section{Competing Interests}

The statistical work performed 25 years ago, were supported by Pharmacia Diagnostics, Uppsala, Sweden. There was no financial support for this publication.

\section{Authors' Contributions}

Christian Moller and Sten Dreborg designed the study and evaluated the results. Margareta Holgersson PhD and Sten Dreborg developed the evaluation methods. Sten Dreborg also wrote the paper and drew the figures. Christian Moller was the investigator. All authors contributed to the original manuscript and Sten Dreborg and Christian Moller designed the final version.

\section{Acknowledgements}

Our sincere thanks to the skin testing nurses who did the original skin testing, as well as to Anders Hansson, BSc, statistician, who performed the computer work.

\section{References}

1. Allergen immunotherapy: a practice parameter (2003) American Academy of Allergy, Asthma and Immunology, American College of Allergy, Asthma and Immunology. Annals of allergy, asthma \& immunology: official publication of the American College of Allergy, Asthma, \& Immunology 90: 1-40.

2. Dreborg S, Holgersson M, Nilsson G, Zetterström O (1987) Dose response relationship of allergen, histamine, and histamine releasers in skin prick test and precision of the skin prick test method. Allergy 42: 117-125.

3. Dreborg S, Basomba A, Belin L, Durham S, Einarsson R, et al. (1987) Biological equilibration of allergen preparations: methodological aspects and reproducibility. Clin Allergy 17: 537-550.

4. Dreborg S (2001) Skin testing in Allergen Standardization and Research. Immunol Allergy Clinics 21: 329-354.

5. McCann WA, Ownby DR (2002) The reproducibility of the allergy skin test scoring and interpretation by board-certified/board-eligible allergists. Ann Allergy Asthma Immunol 89: 368-371.

6. Dreborg S, Frew A (2008) Position Paper: Allergen standardisation and skin tests. Allergy 47: 48-82.

7. Dreborg S (2015) Allergen skin prick test should be adjusted by the histamine reactivity. Int Arch Allergy Immunol 166: 77-80.

8. Dreborg S, Holgersson M (2015) Evaluation of methods for the estimation of threshold concentrations by the skin prick test. Int Arch Allergy Immunol 166: 71-76.

9. Dreborg S, Basomba A, Löfkvist T, Holgersson M, Möller C (2016) Evaluation of skin reactivity during (immuno-) therapy. Validation of methods for estimation of changes in skin reactivity and correlation to shock organ sensitivity. Immunotherapy Open Acc 2: 109.

10. Möller C, Dreborg S (1986) Cross-reactivity between deciduous trees during immunotherapy. I. In vivo results. Clin Allergy 16: 135-143.

11. Dreborg S, Einarsson R (1992) The major allergen content of allergenic preparations reflect their biological activity. Allergy 47: 418-423. 
Citation: Dreborg S, Holgersson M, Moller C (2016) Evaluation of Changes in Skin Reactivity by Skin Prick Test Titration. Immunother Open Acc 2: 116. doi:10.4172/2471-9552.1000116

Page 5 of 5

12. Guidelines for registration and standardization of allergenic extracts (1989). (2ndedn), NLN Publication, Uppsala, Sweden.

13. Pepys J (1968) Skin tests in diagnosis In: Clinical aspects of immunology. (2ndedn), Oxford: Blackwell Scientific Publications, USA.

14. Pepys J (1975) Skin testing. Br J Hosp Med 14: 412-417.

15. Finney D (1978) Statistical methods in biological assays. (3rd edn.), Charles Griffin \& Co Ldt, London.

16. Finney DJ (1976) A computer program for parallel line bioassays. J Pharmacol Exp Ther 198: 497-506.

17. Bland JM, Altman DG (1986) Statistical methods for assessing agreement between two methods of clinical measurement. Lancet i: 307-10.

18. Bernstein IL, Li JT, Bernstein DI, Hamilton R, Spector SL, et al. (2008) Allergy Diagnostic Testing: An Updated Practice Parameter. J Ann Allergy Asthma Immunol 100: S1-S148.
19. Kuhn W, Urbanek R, Forster J, Dreborg S, Burow G (1985) Hyposensibilizierung bei Pollnosis: dreijährige prospektive Vergleichsuntersuchung bei Kindern. Allergologie 8: 103-109.

20. Stuckey MS, Witt CS, Schmitt LH, Warlow R, Lattimore M, et al. (1985) Histamine sensitivity influences reactivity to allergens. J Allergy Clin Immunol 75: 373-376.

21. Bordignon V, Burastero SE (2006) Age, gender and reactivity to allergens independently influence skin reactivity to histamine. J Investig Allergol Clin Immunol 16: 129-135. 